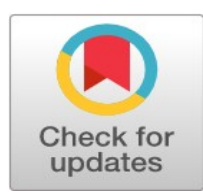

\title{
The importance of control environment in an organization for an independent auditor to determine nature,timing, and extent of substantive tests: An application in Turkey
}

\author{
Sezen Uludăg * \\ Anadolu University, Eskişehir, Turkey
}

\author{
Index Terms \\ Control environment \\ Internal control \\ Substantive tests
}

Received: 24 August 2016

Accepted: 19 November 2016

Published: 19 December 2016

\begin{abstract}
This paper explains the effect of the control environment as one of the components of internal control in performing substantive procedures by auditors. Control environment constitutes the tone of an organization and represents the understanding of control from the point of all of the employees in an organization. So to determine the nature, timing, and extent of substantive test which the auditor will perform to detect material misstatements at the assertion level, auditors should examine the control environment and have a judgment on the structure of the control environment. Because of the holistic effect of the control environment, it is one of the most effective determinants for auditors. Auditors are asked about some factors related to the control environment in Turkey and the frequency of the data analyzed. As a result, the factors of the control environment are examined, and the importance of the control environment in auditors' decisions is emphasized.
\end{abstract}

(C) 2016 The Author(s). Published by TAF Publishing.

\section{INTRODUCTION}

Independent auditors should examine internal control of an organization to determine the nature, timing and extent of substantive tests. They can decide on the nature, timing and extent of substantive tests according to their judgement about the effectiveness of internal control. After some changes in regulations and especially new requirements related with Sarbanes-Oxley Act, understanding internal controls of the clients became a more important action for auditors. Besides International Standards on $\mathrm{Au}-$ diting (ISAs) published by The International Auditing and Assurance Standards Board (IAASB) experts explain the requirement for understanding of internal control. ISA 315 named "Identifying and assessing the risks of material misstatement through understanding the entity and its envi- ronment" indicates that auditors have to constitute an understanding of controls which are relevant to the audit process. Thus examining relevant controls is based on auditors' professional judgement. To examine these relevant controls auditors should evaluate how they are designed and whether they are being implemented effectively (IAASB, 2015:276-277). The best way to explain the importance of evaluating internal control for audit planning phase is explaining generally accepted "audit risk model" because it presents a perfect and functional framework for auditors to plan their process. According to audit risk model, it has 3 components: (Messier Jr, Glover, Prawitt, 2010: 71-72; Arens \& Loebbecke, 2000:259-260), Audit Risk = Inherent Risk X Control Risk X Detection Risk.

Accordingly, evaluating client's internal control means

\footnotetext{
${ }^{*}$ Corresponding author: Sezen Uludağ

${ }^{\dagger}$ Email: sezencubukcu@gmail.com
} 
determining control risk level in planning phase of an audit process. So understanding and internalizing this audit risk model is very important to realize an effective and efficient audit plan. In reference to the audit risk model, audit risk can be defined as a possibility of explaining an inappropriate audit opinion when there are some material misstatements in financial statements of a client. Inherent risk means possibility of occurring of a misstatement which is material before consideration of any related controls. Control risk is a possibility of occurring of a misstatement which is material and cannot be prevented, detected or corrected by internal control. Detection risk is a possibility that exists when auditor's procedures fail at detecting a misstatement which is material (IAASB, 2015). The first two components; inherent risk and control risk are independent from auditor's procedures, they are indigenous for the structure of businesses. They are generating risk of material misstatement together. This perspective clearly explains why auditors should evaluate internal control effectively. After this evaluation they can gain an opinion on the effectiveness of internal control and then they can determine an optimum detection risk. This means they can determine the nature, timing and extent of procedures which can keep total audit risk in the acceptable level. As explained with audit risk model, evaluating of internal control - it means control risk- is a significant determinant to plan an audit process. Based on the auditor's opinion about internal control, the remaining phases will be shaped. Therefore, audit process can be defined as a decision making process and evaluating internal control can be defined as one of the most important stages of this decision making process. Auditors should constitute a logical framework to plan their audit process at first. A basic flowchart to form an opinion regarding the effectiveness of internal control and its relation with substantive procedure is shown below.

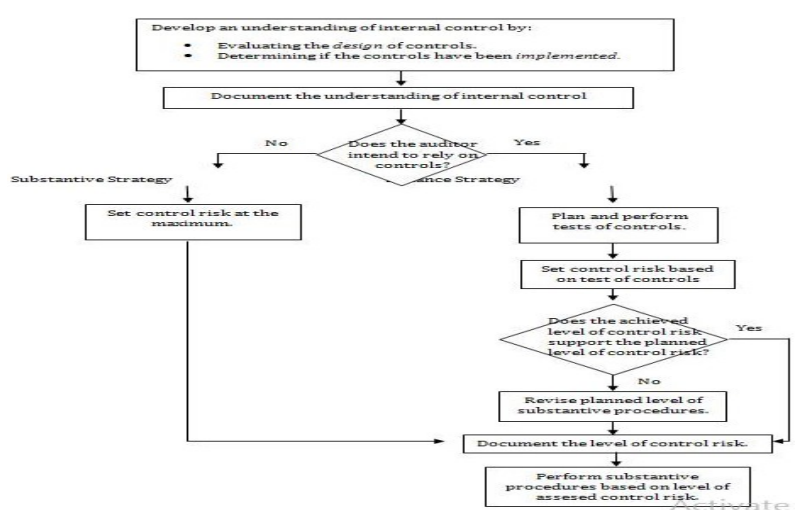

FIGURE 1. Flowchart of the auditor's consideration of internal control and its relation to substantive procedures

ISSN: 2414-309X

DOI: $10.20474 /$ jabs-2.6.4
As shown in Figure 1, auditors should obtain an understanding about internal control at first. It means they have to question the existence and effectiveness of the control procedures. This first step requires auditor's professional judgement. They have to evaluate the design of controls and determine if the controls have been implemented. Eventually a decision about audit strategy is made by the auditor. And auditor has to document the understanding of internal control. With this decision auditor chooses his/her audit strategy. This significant decision is affected by both quantitative and qualitative factors and also professional skepticism of an auditor. To make a decision for an audit strategy, auditors have the alternatives; Substantive strategy and reliance strategy. If an auditor chooses substantive strategy, it means she/he doesn't rely on the client's internal control procedures.

This strategy may be named as no-reliance strategy. Afterwards auditor directly audits the related financial statements. She/he documents the understanding of internal control and determines the control risk at the maximum level. Ultimately substantive tests will be designed and performed according to the control risk at the maximum level (Messier Jr et al., 2010:196-199). As a second alternative auditor may choose reliance strategy after obtaining a preliminary understanding of internal control. This decision means auditor may rely on internal control procedures and design substantive test according to this assessment. But in this case auditor needs more information about internal control. Then she/he performs test of controls according to the planned level of control risk to obtain a better understanding, because she/he wants to be sure if they are really effective or not. After test of controls, auditor can compare the achieved and planned level of control risk. If achieved level supports the planned level of control risk, auditor can document the level of control risk and then perform substantive procedures based on level of assessed control risk. But if does not support the planed risk auditor needs to revise planned level of substantive procedures.

After that revision auditor can document the level of control risk and then perform substantive procedures based on level of assessed control risk (Messier Jr et al., 2010:199-200). In this alternative if control risk can be determined in an appropriate low level; in other words if auditor can rely on control procedures, it means auditor can decrease the extent of the substantive tests. As a result, it can be said that auditor's decision about understanding of internal control is the most determinant evaluation in the planning phase of the audit. For this reason, it should con- 
sider the internal control structure which will be evaluated because this is the structure over which auditor will establish his/her opinion. As is known internal control is defined by Committee of Sponsoring Organizations of the Treadway Commission (COSO) (n.d) as "A process, affected by an entity's board of directors, management, and other personnel, designed to provide reasonable assurance regarding the achievement of objectives relating to operations, reporting and compliance" (www.coso.org). COSO model is a generally accepted framework for an internal control structure. COSO model also defines the components of internal control as follows (www.coso.org):

a) Control environment

b) Risk assessment

c) Control activities

d) Information and communication

e) Monitoring activities

\section{Objectives of the Study}

As explained above, internal control consists of five main components. Generally, to show the COSO model, a cube is used.

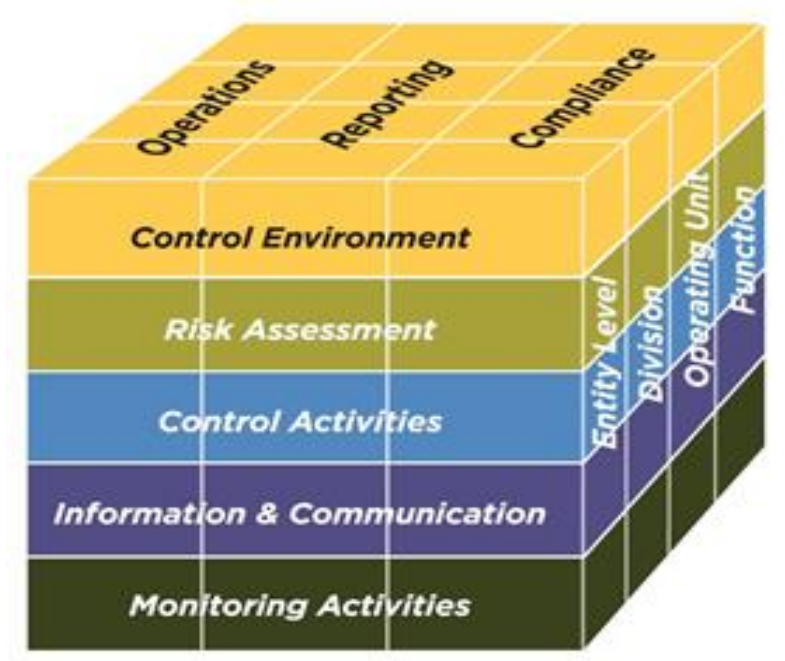

FIGURE 2. COSO cube (www.coso.org)

COSO cube, five components can be seen on the front face, at the top with vertical lines three categories of objectives can be seen and organizational structure of the businesses can be seen by the third dimension. COSO cube illustrates a general framework for an internal control structure. Control environment is one of the components of COSO model. It means tone of an organization so it is also a foundation for other components. In other words, control environment covers all components of the structure and presents a basis to perform effective control procedures. So it is sometimes likened to an umbrella for this model (Messier Jr et al., 2010:191). Establishing an effective, efficient and reliable internal control structure is under the responsibility of management. Therefore, if management fails to generate an effective control environment, it will be impossible and meaningless to establish other components. Because of being a foundation, control environment has a critical importance to evaluate internal control. Consequently, the objective of this study is to analyze the factors which are effective in a control environment. For this aim, a sample from Turkey will be examined and the importance of control environment in an organization for an independent auditor to determine, nature, timing and extent of substantive tests will be emphasized.

\section{LITERAT URE REVIEW}

Because of the importance of both quantitative and qualitative factors in auditors' decision making process, the analysis of this process is critical. Therefore, in auditing literature there are many different studies related with auditors' decision process. As explained above, one of the critical decisions which are made in the auditing process is to determine the nature, timing and extent of substantive tests. In literature, different authors study this subject and related issues from different perspectives. Kinney (1975) explains the problem of audit evidence through the economic combination of audit tests. Statement on Auditing Standards No.1 (SAS No. 1) explains the procedures in two different categories: The first one is the evaluation of internal control and the second one is substantive tests. Evaluation of internal control by reviewing of system design and performing test of compliance designate the judgement on the strength of internal control.

This judgement determines the level of assurance related with reported balances that are not materially in error, so auditor can determine the extent of substantive tests. In this evaluation process parameter specification is very complex and developing a complete decision theory model is difficult. As a result, it is tried to explain how the approach can be operationalized with a numerical example and the differences between traditional compliance testing (Kinney, 1975). Smieliauskas (1980) discusses whether the reliability of audit can be maintained while subsequent audit procedures are reduced by a judgement about internal control. The results of the study shows that the statistical validity of the internal control hypothesis has been confirmed even 
when internal control reliance results in the smaller substantive test sample sizes are likely to be used in an actual audit (Smieliauskas, 1980). Gaumnitz, Nunamaker, Surdick \& Thomas (1982) discuss the relation between auditors' internal control evaluations and audit program planning. As explained in the paper, previous studies have different results about this relation. According to results of Gaumnitz et al. (1982) the consensus is achieved in their paper about both internal control evaluation and audit planning tasks. They suggest strength of internal control is linked to audit hours' judgements (Gaumnitz et al., 1982). Biggs \& Mock (1983) focus on the variation of auditors' judgement related with internal control and audit scope decision points. They try to explain why the auditors make different decisions and how difficult to evaluate their behaviors in complex tasks (Biggs \& Mock, 1983).

Srinidhi \& Vasarhelyi (1986) explain the internal control evaluation process in three basic stages: Identification, evaluation and interpretation. Auditors constitute their decision whether they can restrict their substantive tests in the last stage regarding the strength of the internal control. In this context, auditors' interpretation of internal control strength in terms of planned substantive audit test restriction is analyzed. The results show that auditors disagree on how to aggregate evidence. But if there is an aggregation rule they can follow high consensus (Srinidhi \& Vasarhelyi, 1986). Wilson \& Colbert (1991) explain that auditors' objectives usually can be achieved with less time and cost by applying analytical procedures rather than tests of details. As a result, they emphasize on the importance of using analytical procedures for cost effective strategies (Wilson \& Colbert, 1991). Johnston (1992) discuss the need for a new understanding related with internal control with some new regulations. According to the new grip that is needed, auditors have to obtain and document an understanding of internal control to plan their audit process and perform a risk-based approach in this process. These new requirements emphasize the role of effective control environment it can play in the audit process (Johnston, 1992). Craig examines the process that auditors evaluate clients' internal control over inventory and make decisions regarding the appropriate amount of substantive tests.

However, this process is also affected by professional judgement. According to this point of view, Craig examines two factors which may influence auditors' decisions. These factors are framing and presentation. As a result, the effect of interaction between these factors and the relation between auditors' decisions related with substantive testing decision and evaluation of internal control are addressed. Auditors increased the amount of substantive tests they felt to be appropriate after receiving the additional information (Emby, 1994). Kinney Jr \& McDaniel (1996) suggest a subjective approach to assess the precision of expectations and discuss the related factors in this process like inherent precision, analytical methods applied and data used. In conclusion, they emphasize to think about reasonable expectations at the time of the audit (Kinney Jr \& McDaniel, 1996). Smith, Tiras \& Vichitlekarn (2000) discuss the fraud situations with regards to auditor and manager interaction in two-stage model. In the first stage auditor assesses the probability of a fraud, then in the second stage conduct substantive tests. As a result, spending resources on internal control assessment cannot change the probability of undetected fraud but these assessments can provide a cost saving (Smith et al., 2000). Cohen \& Hanno (2000) discuss the importance of corporate governance and management control philosophy.

They examine the relation between these factors and preplanning and planning judgements. In conclusion, management control philosophy and corporate governance affect the preplanning and planning judgements. They highlight the effect of control environment on these judgements (Cohen \& Hanno, 2000). Doyle, Ge \& McVay (2007) discuss the determinants of weaknesses in internal control. They explain the characteristics of firms with more serious entity-wide control problems. Firms which have control weaknesses are smaller, younger, financially weaker, more complex, growing rapidly, or undergoing restructuring. As a result, they highlight that the determinants may vary based on the specific reason for the material weakness (Doyle et al., 2007). Hogan \& Wilkins (2008) highlight the effects of Internal Control Deficiencies (ICD) in an audit process. They examine if the reason of the relation between audit fees and ICD is based on the requirement of making more effort in a business which has some ICD. This research also reveals practicability of the audit risk model because it requires making extra effort in the businesses which have ICD to keep audit risk at an acceptable level. The results of the paper show that audit fees are significantly higher for the businesses which have some ICD (Hogan \& Wilkins, 2008). Rice \& Weber (2012) examine the determinants according to internal control reporting decisions. The basis for this examination is Section 404 of the Sarbanes-Oxley Act (SOX 404). In conclusion, many firms which are in the sample of the study and their auditors fail to report some control weaknesses. 
They highlight the importance of understanding the conditions that cause nondisclosure of some control weaknesses (Rice \& Weber, 2012). Asare et al. (2012) analyze and synthesize the literature related with evaluation and reporting of Internal Control Over Financial Reporting (ICOFR). They suggest task taxonomy for ICOFR, providing determinants for each phase. Consequently, their findings provide insights for standard setters, practitioners, and academics related with ICOFR decisions (Asare et al., 2012). Weng, Chi \& Chen (2015) discuss some effects of internal control weakness on the precision of information. As is explained in the paper, public and private information are constituted of a firm's information environment. The result of the paper presents that firms have weak internal control environment and systems have less precise information. Moreover, the results indicate that public and private information precision will be adversely affected by weak internal controls. According to these results, it is suggested that information asymmetry and the level of information uncertainty can be reduced by improving of weak controls (Weng, et al., 2015).

Güner (2010) describes control environment as a factor of internal control that can be shaped by history, culture and business style of an organization. And he analyzed control environment of a public administration (Güner, 2010). With this literature review basic studies related with determining the nature, timing and extent of substantive tests and related subject are covered. Different from those, this study focuses on a control environment while evaluating internal control and determining the nature, timing and extent of substantive test. This study may have a contribution to literature by analyzing the effect and importance of control environment which is a critical internal control component in audit planning phase.

\section{RESEARCH METHODOLOGY}

As explained above, control environment is a fundamental component of internal control because it presents a basis for all other components. Auditors need to gain an understanding of control environment because they want to know management's attitude, awareness and actions about control (Messier Jr et al., 2010:190-191). Also they want to understand control consciousness in the business which should be indigenized by all employees. According to the literature and ISAs, there are some factors or elements which are affecting control environment. An evaluation of these factors can provide an understanding about control environments (IAASB, 2015:301; Messier Jr et al., 2010:191-192; Arens \& Loebbecke, 2000:293-294). These factors can be summarized as follows (IAASB, 2015:301-302):

a) Communication and enforcement of integrity and ethical values

b) Commitment to competence

c) Participation by those charged with governance

d) Management's philosophy and operating style

e) Organizational structure

f) Assignment of authority and responsibility

g) Human resource policies and practices

Communication and enforcement of integrity and ethical values can affect all control procedures. They must be general principles to establish effective control procedures. According to requirement for commitment to competence there must be formal/informal job definitions and management should consider the competence level for each job. Participation by those charged with governance may have a pervasive effect on the general control consciousness. Another significant effect is related with the management's philosophy and operating style. Some characteristics about this factor may be very important like approach to taking and managing business risks, actions toward financial reporting process etc. Having an appropriate organizational structure is also critical because it means a base for all other factors. Assignment of authority and responsibility also provides an understanding for organizational hierarchies. Effective human resource policies and practices should be established. Because this factor may affect internal control quality directly.

An effective control environment can be an important positive factor in assessing the risk of material misstatement. Moreover, it may reduce the fraud risk. To get the advantage of an effective control environment, the management of a business not only establishes the factors of control environment but also activates them. Similarly, an auditor should focus on the substance of the factors of control environment rather than their forms to gain an understanding of the effectiveness of control environment. As explained in ISA 330 named "The Auditor's Responses to Assessed Risks" the control environment can affect the nature, timing and extent of substantive tests (IAASB, 2015:301-303, Messier Jr et al., 2010:190-1922).

With this perspective, in this study according to the general framework for control environment, 160 audit works are examined in an international audit firm which operates also in Turkey by face to face interviews with 16 auditors. Each auditor answers the questions about their 10 differ- 
ent audit works. Some questions related with the existence and effectiveness of control environment are asked and also auditor's judgement about the probability of decreasing the extent of substantive tests regarding their preliminary judgement are asked. Data obtained from interviews are analyzed through SPSS Statistics 20 (Statistical Package for the Social Sciences) and the descriptive statistics of the data discussed. This study is a sample application in Turkey and interviews are performed in just one audit firm for 160 audit works. These are limitations of the study, the sample size may extend and the audit firms may vary in future researches.

\section{RESULT S}

Some questions about the existence and effectiveness of seven factors related with the structure of a control environment in a business were asked to the auditors. The table 1 below summarizes the frequency and percentage of these factors.

TABLE 1 . The frequency and percentage of the factors related with control environment

\begin{tabular}{lccc}
\hline \hline Factors of Control Environment & & Frequency & Percentage \\
\hline Principles related with integrity and ethical values & Exist effectively & 154 & $96.3 \%$ \\
& Nonexistence/Ineffective & 6 & $3.8 \%$ \\
Commitment to competence & Exist effectively & 142 & $88.8 \%$ \\
& Nonexistence/Ineffective & 18 & $11.3 \%$ \\
Monitoring activities of board of directors and audit committee & Exist effectively & $12678.8 \%$ & \\
& Nonexistence/Ineffective & 34 & $21.3 \%$ \\
Management's philosophy and operating style & Exist effectively & 145 & $90.6 \%$ \\
& Nonexistence/Ineffective & 15 & $9.4 \%$ \\
Determination of job definitions in an appropriate organizational structure & Exist effectively & 138 & $86.3 \%$ \\
& Nonexistence/Ineffective & 22 & $13.8 \%$ \\
Assignment of authority and responsibility & Exist effectively & 119 & $74.4 \%$ \\
Nonexistence/Ineffective & 41 & $25.6 \%$ & \\
Human resource policies and practices & Exist effectively & 148 & $92.5 \%$ \\
& Nonexistence/Ineffective & 12 & $7.5 \%$ \\
\hline \hline
\end{tabular}

As shown in table 1, seven questions are asked to the auditors to understand existence and effectiveness of their clients' control environment. Firstly, effective existence of "Principles related with integrity and ethical values" is questioned. Principles related with integrity and ethical values exist effectively in 154 (96.3\%) clients but in 6 (3.8\%) clients, they do not exist or they are ineffective. Secondly effective existence of "Commitment to competence" is questioned. Commitment to competence exists effectively in $142(88.8 \%)$ clients but in 18 (11.3\%) clients, it does not exist or it is ineffective. Then effective existence of "Monitoring activities of board of directors and audit committee" is questioned. Monitoring activities of board of directors and audit committee exists effectively in 126 (78.8\%) clients but in $34(21.3 \%)$ clients, it does not exist or it is ineffective. Then "Management's philosophy and operating style" is questioned to learn whether clients have an effective management's philosophy and operating style. According to answers, 145 (90.6 \%) clients have an effective management's philosophy and operating style but 15 (9.4\%) clients don't have a management's philosophy and operating style or they have an inefficient management's philosophy and operating style. Then "Determination of job definitions in an appropriate organizational structure" is questioned. Determination of job definitions in an appropriate organizational structure exists effectively in 138 (86.3\%) clients but in 22 (13.8\%) clients, it does not exist or it is ineffective. Then "Assignment of authority and responsibility" is questioned. Assignment of authority and responsibility exists effectively in 119 (74.4\%) clients but in $41(25.6 \%)$ clients, it does not exist or it is ineffective.

At last "Human resource policies and practices" are questioned to learn whether clients have effective human resource policies and practices. According to answers, 148 $(92.5 \%)$ clients have effective human resource policies and practices but 12 (7.5\%) clients don't have human resource policies and practices or they have inefficient Human resource policies and practices. Auditors' judgements on probability to reduce the extent of substantive tests before examining any components of clients' internal control are also asked to the auditors (as a sense, perception, bias etc.). They are wanted to express their judgements with percentages. These percentages are based on their experiences, knowledge, personality etc. Below, table 2 summarizes the auditors' judgements on probability to reduce the extent of substantive tests. 
TABLE 2 . The frequency and percentage of the auditors' judgements

\begin{tabular}{lcc}
\hline \hline Probability & Frequency & Percentage \\
\hline $0 \%$ & 1 & $0.6 \%$ \\
$5 \%$ & 1 & $0.6 \%$ \\
$10 \%$ & 25 & $15.6 \%$ \\
$15 \%$ & 1 & $0.6 \%$ \\
$20 \%$ & 4 & $2.5 \%$ \\
$25 \%$ & 9 & $5.6 \%$ \\
$30 \%$ & 2 & $1.3 \%$ \\
$35 \%$ & 1 & $0.6 \%$ \\
$40 \%$ & 9 & $5.6 \%$ \\
$45 \%$ & 1 & $0.6 \%$ \\
$50 \%$ & 26 & $16.3 \%$ \\
$60 \%$ & 13 & $8.1 \%$ \\
$65 \%$ & 1 & $0.6 \%$ \\
$70 \%$ & 28 & $17.5 \%$ \\
$75 \%$ & 6 & $3.8 \%$ \\
$80 \%$ & 11 & $6.9 \%$ \\
$90 \%$ & 19 & $11.9 \%$ \\
$100 \%$ & 2 & $1.3 \%$ \\
\hline \hline
\end{tabular}

According to the data in table 2 auditors' judgements vary by percentages. As shown in the Table 2, there is 1 audit in this case in which auditor's judgement on probability to reduce the extent of substantive tests is $0 \%$. And similarly 1 audit which has a probability 5\%, 15\%, 35\%, 45\% and $65 \%$. There are 4 audits in this case in which auditor's judgement on probability to reduce the extent of substantive tests is $20 \%$. There are 9 audits in this case in which auditor's judgement on probability to reduce the extent of substantive tests is $25 \%$ and similarly 9 audits which have a probability of $40 \%$. There are 2 audits in this case in which auditors' judgement on probability to reduce the extent of substantive tests is $30 \%$ and similarly 2 audits which have a probability of $100 \%$. There are 26 audits in this case in which auditor's judgement on probability to reduce the extent of substantive tests is $50 \%$.

There are 13 audits in this case in which auditor's judgement on probability to reduce the extent of substantive tests is $60 \%$. There are 28 audits in this case in which auditor's judgement on probability to reduce the extent of substantive tests is $70 \%$ (this is the most frequent one). There are 6 audits in this case in which auditor's judgement on probability to reduce the extent of substantive tests is $75 \%$. There are 11 audits in this case in which auditor's judgement on probability to reduce the extent of substantive tests is $80 \%$ and at last there are 19 audits in this case in which auditor's judgement on probability to reduce the extent of substantive tests is $90 \%$.

\section{DISCUSSION AND CONCLUSION}

According to the results, generally all of the factors exit effectively to a large extent in businesses that auditors examine. It can be said that clients try to establish an effective control environment. Based on the results the first factor of control environment named "Principles related with integrity and ethical values" is the most frequent one and the sixth factor named "Assignment of authority and responsibility "is the least frequent one. So it is the most problematic factor of control environment in this case. As known especially with the effects of some corporate scandals, principles related with integrity and ethical values became significant. Their importance is understood clearly all over the world. This understanding leads to new requirements and regulations.

Thanks to new regulations like ethical principles and standards and also the requirements for ethical behaviors for corporate governance, principles related with integrity and ethical values became very important and prevalent. Also in Turkey the importance of principles related with integrity and ethical values is understood clearly. So the results also show that clients are giving required importance to principles related with integrity and ethical values. Con- 
versely assignment of authority and responsibility is the least frequent control environment factor. The reason for this situation may be due to the customs coming from prevalent family-owned enterprises because there may be some important deficiencies in assignment of authority and responsibility in family-owned enterprises. Now many companies are following the requirements for corporate governance but especially sometimes customs coming from prevalent family-owned enterprises may still have some effects on the way of governing.

In the other words, the reason for deficiencies in assignment of authority and responsibility may be some factors related with socio-cultural structure of Turkish people. Results also show that auditors have different judgements for each client so their judgements vary by percentages. After that the data related with effective existence of the factors and auditors' judgements for the most and the least frequent factors are examined together to understand and interpret the results correctly.

The number of the clients who do not have "Principles related with integrity and ethical values"(factor 1) or have ineffective "Principles related with integrity and ethical values" are just 6. For 3 of them, auditor's judgement on probability to reduce the extent of substantive tests is $50 \%$ at most and for remaining 3 clients, this probability is more than 50\%. The number of the clients whose "Assignment of authority and responsibility" (factor 6) does not exist or clients who have an ineffective way of "Assignment of authority and responsibility" are 41 . For 30 of them auditor's judgement on probability to reduce the extent of substantive tests is $50 \%$ at most and for remaining 11 this probability is more than $50 \%$. Below, table 3 and 4 gives the details about percentages for these two factors.

TABLE 3 . The frequency of clients who do not have factor 1 or an ineffective factor 1 and the percentage of auditor's judgement on probability to reduce the extent of substantive tests

\begin{tabular}{lccccccccccccc}
\hline \hline Probability & $\% 0$ & $\% 5$ & $\% 10$ & $\% 15$ & $\% 20$ & $\% 25$ & $\% 30$ & $\% 35$ & $\% 40$ & $\% 50$ & $\% 60$ & $\% 70$ & $\% 90$ \\
Frequency & 1 & 1 & 6 & 1 & 3 & 5 & 1 & 1 & 7 & 4 & 2 & 8 & 1 \\
\hline \hline
\end{tabular}

TABLE 4 . The frequency of clients who do not have factor 6 or an ineffective factor 6 and the percentage of auditor's judgement on probability to reduce the extent of substantive tests

\begin{tabular}{lccccc}
\hline \hline Probability & $\% 10$ & $\% 50$ & $\% 60$ & $\% 70$ & $\% 90$ \\
Frequency & 2 & 1 & 1 & 1 & 1 \\
\hline \hline
\end{tabular}

Surely all factors of control environment are very important and effective for auditors to constitute a judgement on the probability to reduce the extent of substantive tests and plan their audit process. According to the results related with the most frequent (factor 1 ) and least frequent (factor 6) factor especially for this case, it can be said that if there is a deficiency in principles related with integrity and ethical values which is the most frequent factor, this situation may affect auditor's judgement on probability to reduce the extent of substantive tests negatively. The auditors' judgements on probability to reduce the extent of substantive tests are more than $50 \%$ for only 3 clients in spite of their deficiencies in having effective principles related with integrity and ethical values. For all other clients who have deficiencies in having effective principles related with integrity and ethical values, auditors' judgements on probability to reduce the extent of substantive tests are at most 50\%. It means deficiencies in having effective principles related with integrity and ethical values are not too much acceptable for establishing an effective control environment. As a result, in this case it is seen that to establish an effective control environment it is so important to have effective principles related with integrity and ethical values and this factor may affect auditors' judgements on probability to reduce the extent of substantive tests. Because they can rely on the effectiveness of clients' control environment if they understand that clients have effective principles related with integrity and ethical values and choose the reliance strategy.

For the results related with the least frequent (factor 6) factor especially for this case, it can be said that if there is a deficiency in assignment of authority and responsibility, this situation also may affect auditor's judgement on probability to reduce the extent of substantive tests negatively but 
by less than the factor 1 . In this case auditors' judgements on probability to reduce the extent of substantive tests are more than $50 \%$ for 11 clients, inspite of their deficiencies in assignment of authority and responsibility. Surely factor 6 is also very important and effective factor like all others but in this case it can be said that factor 6 can affect auditor's judgement on probability to reduce the extent of substantive tests by less than factor 1 . This result shows that deficiencies in assignment of authority and responsibility may be sometimes allowable because of some customs and usual way of working in Turkey as explained above. Actually not many clients have deficiencies but some clients still have. Ultimately deficiencies in assignment of authority and responsibility are less effective on the auditor's judgement on probability to reduce the extent of substantive tests than deficiencies in having effective principles related with integrity and ethical values.

\section{IMPLICATIONS}

Consequently, having effective principles related with integrity and ethical values is a basic factor. As explained in this paper control environment is like an umbrella for internal control (Messier Jr et al., 2010:191). From this point of view, having effective principles related with integrity and ethical values is also like an umbrella for control environ- ment. It can establish a base for an effective control environment. Surely all factors of control environment are very important and effective for auditors to constitute a judgement on the probability to reduce the extent of substantive tests and plan their audit process. As a result, control environment is a very significant component to constitute auditors' judgements on probability to reduce the extent of substantive tests and planning the audit process. All of the factors of control environment must be very important, but especially principles related with integrity and ethical values may be very effective as in one of the applications in Turkey.

So for clients it is very important to establish an effective control environment. For auditors understanding the clients' control environment truly at first and then all of the internal control is very important to choose a correct strategy and to have an efficient and effective audit plan. This phase is a vital part of their audit process based on level of assessed control risk because auditors' judgements on clients' control environment may have effects on shaping all of the audit process.

\section{Acknowledgment}

I would like to thank Prof. Dr. Nurten Erdogan and Prof. Dr. Melih Erdogan for their valuable guidance and support.

\section{REFERENCES}

Arens, A.A., \& Loebbecke, J.K. 2000. Auditing an integrated approach. New Jersey, NJ: Prentice Hall.

Asare, S.K., Fitzgerald, B.C., Graham, L.E., Joe, J.R., Negangard, E.M., \& Wolfe, C.J. 2012. Auditors' internal control over finan- cial reporting decisions: Analysis, synthesis, and research directions. Auditing: A Journal of Practice \& Theory, 32(sp1): 131-166. DOI: 10.2139/ssrn.2032822

Biggs, S.F., \& Mock, T.J. 1983. An investigation of auditor decision processes in the evaluation of internal controls and au- dit scope decisions. Journal of Accounting Research, 21(1): 234-255. D0I: 10.2307/2490945

Cohen, J.R., \& Hanno, D.M. 2000. Auditors' consideration of corporate governance and management control philosophy in preplanning and planning judgments. Auditing: A Journal of Practice \& Theory, 19(2): 133-146.

DOI: 10.2308 /aud.2000.19.2.133

Committee of Sponsoring Organizations (COSO). n.d. Integrated framework. URL: goo.gl/IZxM4l. Last accessed on 16 June 2016.

Emby, C. 1994. Framing and presentation mode effects in professional judgment: Auditors' internal control judgments and substantive testing decisions. Auditing: A Journal of Practice \& Theory, 13(1): 102-115.

Doyle, J., Ge, W., \& McVay, S. 2007. Determinants of weaknesses in internal control over financial reporting. Journal of Ac- counting \& Economics, 44(1): 193-223. D0I: 10.1016/j.jacceco.2006.10.003

Gaumnitz, B.R., Nunamaker, T.R., Surdick, J.J., \& Thomas, M.F. 1982. Auditor consensus in internal control evaluation and audit program planning. Journal of Accounting Research, 20(2): 745-755. D0I: 10.2307/2490898

Güner, F. 2010. Evaluation of control environment: A case study in a public administration. The Journal of Accounting \& Finance, 46: 189-198.

Hogan, C.E., \& Wilkins, M.S. 2008. Evidence on the audit risk model: Do auditors increase audit fees in the presence of internal control deficiencies. Contemporary Accounting Research, 25(1): 219-242. D0I: 10.1506/car. 25.1.9 
International Auditing and Assurance Standards Board (IAASB). 2015. Handbook of international quality control, au- diting, review, other assurance, and related services pronouncements. URL: goo.gl/gS2e1Q. Last accessed on 22 April 2016.

Johnston, R.R. 1992. A new grip on internal control. CA Magazine, 125(4): 63-66.

Kinney, W. R. 1975. Decision theory aspects of internal control system design/compliance and substantive tests. Journal of Accounting Research, 13(1): 14-29. DOI: 10.2307/2490473

Kinney Jr, W. R., \& McDaniel, L.S. 1996. How to improve effectiveness of substantive analytical procedures. The CPA Journal, 66(4): 52-54.

Messier Jr, W.P., Glover, S.M., \& Prawitt, D.F. 2010. Auditing and assurance services a systematic approach. New York, NY: McGraw-Hill.

Rice, S.C., \& Weber, D.P. 2012. How effective is internal control reporting under SOX 404? Determinants of the (non-) disclo- $\quad$ sure of existing material weaknesses. Journal of Accounting Research, 50(3): 811-843.

DOI: $10.1111 / \mathrm{j} .1475-679 X .2011 .00434 . x$

Smieliauskas, W.J. 1980. Simulation analysis of the statistical validity of the internal control hypothesis of auditing with implication for substantive testing methods and linkage rules. Unpublished doctoral dissertation, University of Wisconsin-Madison, US.

Smith, J., Tiras, S.L., \& Vichitlekarn, S.S. 2000. The interaction between internal control assessment and substantive testing in audits for fraud. Contemporary Accounting Research, 17(2): 327-356. D0I: 10.1506/P7V7-1VUY-0QP8-5W7U

Srinidhi, B.N., \& Vasarhelyi, M.A. 1986. Auditor judgment concerning establishment of substantive tests based on internal control reliability. Auditing: A Journal of Practice \& Theory, 5(2): 64-76.

Weng, T.C., Chi, H.Y., \& Chen, G.Z. 2015. Internal control weakness and information quality. Journal of Applied Finance \& Banking, 5(5): 135-169.

Wilson, A.C., Colbert, J.L. 1991. The audit strategy: Analytical procedures as substantive tests. The National Public Accoun36(5): 38-41. 